OPEN ACCESS

Edited by:

Fabian Cieplik,

University Medical Center

Regensburg, Germany

Reviewed by:

Mariusz Stanislaw Grinholc,

Intercollegiate Faculty

of Biotechnology of University

of Gdańsk and Medical University

of Gdańsk, Poland

Tamás Papp,

University of Szeged, Hungary

Tim Maisch

University of Regensburg, Germany

*Correspondence:

Libao Zheng

fzspzlb@126.com;

13805012134@126.com

Jingjun Zhao

zhaomyco@163.com

Specialty section:

This article was submitted to Antimicrobials, Resistance

and Chemotherapy,

a section of the journal

Frontiers in Microbiology

Received: 03 December 2018

Accepted: 16 May 2019

Published: 07 June 2019

Citation:

Chen B, Sun Y, Zhang J, Chen R, Zhong $X$, Wu $X$, Zheng $L$ and Zhao J

(2019) In vitro Evaluation of Photodynamic Effects Against Biofilms of Dermatophytes Involved in Onychomycosis.

Front. Microbiol. 10:1228. doi: $10.3389 /$ fmicb.2019.01228

\section{In vitro Evaluation of Photodynamic Effects Against Biofilms of Dermatophytes Involved in Onychomycosis}

\author{
Borui Chen 1,2, Yi Sun ${ }^{3}$, Jinyan Zhang ${ }^{2}$, Ruijun Chen², Xiurong Zhong ${ }^{4}$, Xiaomo $\mathrm{Wu}^{2}$, \\ Libao Zheng ${ }^{2 *}$ and Jingjun Zhao ${ }^{1 *}$
}

\begin{abstract}
${ }^{1}$ Department of Dermatology, Tongji Hospital, Tongji University School of Medicine, Shanghai, China, ${ }^{2}$ Dermatology Hospital of Fuzhou, Fuzhou, China, ${ }^{3}$ Department of Dermatology, Jingzhou Central Hospital, The Second Clinical Medical College, Yangtze University, Jingzhou, China, ${ }^{4}$ Electron Microscopy Laboratory, Fujian Medical University, Fuzhou, China
\end{abstract}

Dermatophytes are the most common cause of onychomycosis, counting for $90 \%$ fungal nail infection. Although dermatophyte pathogens are normally susceptible to antifungal agents, onychomycosis often results in refractory chronic disease, and the formation of biofilms frequently underlines the inadequate responses and resistance to standard antifungal treatment. Numerous in vitro and in vivo antimicrobial photodynamic therapy (aPDT) studies have shown biofilm eradication or substantial reduction, however, such investigation has not yet been expanded to the biofilms of dermatophytes involved in onychomycosis. To shed a light on the potential application of aPDT in the clinic management of onychomycosis, in particular with the manifestation of dermatophytoma, we investigated photodynamic effects on the viabilities and the drug susceptibilities of the biofilm of dermatophytes in vitro. Here, methylene blue at the concentration of 8,16 , and $32 \mu \mathrm{g} / \mathrm{ml}$ applied as photosensitizing agent and LED $\left(635 \pm 10 \mathrm{~nm}, 60 \mathrm{~J} / \mathrm{cm}^{2}\right)$ as light source were employed against six strains of Trichophyton rubrum, ten strains of Trichophyton mentagrophytes and three strains of Microsporum gypseum isolated from clinical specimens. Our results indicated highly efficient photodynamic inhibition, exhibiting CFU (colony forming unit) reduction up to $4.6 \log _{10}, 4.3 \log _{10}$, and $4.7 \log _{10}$ against the biofilms formed by T. rubrum, T. mentagrophytes, and M. gypseum, respectively. Subjected biofilms displayed considerable decreases in SMICs (sessile minimum inhibitory concentrations) to multiple antifungal agents when compared with untreated groups, indicating the biofilms of dermatophytes became more susceptible to conventional antifungal drugs after aPDT. Additionally, the obliteration of biofilm after aPDT could be observed as shattered and ruptured structures being evident in SEM (Scanning Electron Microscopy) images. These findings suggest that aPDT is an attractive alternative treatment holding great promise for combating recalcitrant onychomycosis associated with the biofilm formation.

Keywords: dermatophytes, biofilm, onychomycosis, aPDT, dermatophytoma 


\section{INTRODUCTION}

Onychomycosis is the most prevalent onychopathy that comprises $50 \%$ of nail disorders worldwide (Gupta et al., 2017). Dermatophytes are the predominant pathogens, followed by non-dermatophyte molds and yeasts responsible for approximately $10 \%$ of onychomycosis. Although dermatophytic pathogens are normally susceptible to antifungal agents, it is estimated that only $25-50 \%$ of patients with onychomycosis are cured after the standard treatment (Evans and Sigurgeirsson, 1999; Sigurgeirsson et al., 2002; Gupta et al., 2004; Baran et al., 2007). The presence of biofilm is considered to be a major contributing factor to the recalcitrance of chronic dermatophytic infection refractory to conventional antifungal regimes (Burkhart et al., 2002; Warshaw et al., 2005; Nusbaum et al., 2012; Costa-Orlandi et al., 2014).

Biofilm is a sessile microbial community in which microbes are embedded in highly compacted self-produced matrix of extracellular polymeric substances (EPS), composed of polysaccharides, proteins, extracellular DNA, membrane vesicles, etc (Al-Fattani and Douglas, 2006; Martins et al., 2010; Rajendran et al., 2013). The formation of biofilm is crucial for the microbial survival, sheltering microbes from a variety of environmental assaults, such as desiccation, UV-irradiation, antibiotics, and host immune system (Ceri et al., 2001; Ramage et al., 2012; CostaOrlandi et al., 2014). Comparing to free-floating planktonic cells of the same species, biofilm pathogens can tolerate as much as 1000-fold higher levels of antimicrobial agents (Hawser and Douglas, 1995; Donlan and Costerton, 2002; Marsh, 2004) and microbial biofilms thereby account for more than $60 \%$ of all fungal and bacterial infections in humans (Cieplik et al., 2018).

Antimicrobial photodynamic therapy (aPDT) had been recently proposed to combat biofilms clinically (Lyon et al., 2011; Cieplik et al., 2014; Baltazar et al., 2015). As a non-antibiotic approach, aPDT employs non-toxic photosensitizers (PSs) and visible light at specific wavelength to generate reactive species of oxygen (ROS) and nitrogen (RNS), which are capable of killing microbes (Hamblin and Hasan, 2004; Alves et al., 2014; Taraszkiewicz et al., 2015). Notably, cytotoxic radicals produced by aPDT have extremely short half-lives and react only in their sites of formation, which reduces the cytotoxicity to adjacent normal tissues (Dai et al., 2009; Baltazar et al., 2015). Numerous in vitro as well as some in vivo aPDT studies have demonstrated aPDT has a broad-spectrum of activity against the biofilms and susceptible fungal pathogens and bacterial species include yeast (Candida. spp.), non-dermatophyte molds (Fusarium spp., Exophiala spp.), $\mathrm{G}^{+}$bacteria (S. aureus, E. faecalis, and Streptococcus spp.) and $\mathrm{G}^{-}$bacteria (P. aeruginosa and Aggregatibacter. actinomycetemcomitans) (Gilaberte et al., 2011; Junqueira et al., 2012; Seth et al., 2013; Beirao et al., 2014; Mannucci et al., 2014; Orlandi et al., 2014; Al-Ahmad et al., 2016; Gao et al., 2016; Carvalho et al., 2018).

However, the application of aPDT to biofilms formed by dermatophytes is less studied (Ali et al., 2016; Toukabri et al., 2018) and treatment with high efficacy remains challenging in clinic (Burkhart et al., 2002; Arrese and Pierard, 2003; Sigurgeirsson, 2010). Moreover, there are increasing rates of antimicrobial resistance among dermatophytes, especially for Trichophyton rubrum, the most frequent etiologic agent for onychomycosis (Baltazar et al., 2015). In an attempt to gain insight into the potential clinical implementation of aPDT tackling the dermatophytic biofilms implicated in onychomycosis, we investigated photodynamic effects on the viabilities, and the drug susceptibilities of the biofilm of dermatophytes, ranging from T. rubrum, T. mentagrophytes to M. gypseum.

\section{MATERIALS AND METHODS}

\section{Fungal Strains}

Six strains of T. rubrum (Nos. 16463, 16355, 41452, 41467, 16618, and 41453), ten strains of T. mentagrophytes (Nos. 7240, 5614, 16446, 16339, 16494, 16077, MYA-4439, 8395, 8396, and 8397), and three strains of M. gypseum (Nos. 13789, 8305, and 8825) were supplied by the research center of medical mycology of Peking University (RCMMPU). All analyzed clinical isolates were collected from patients with onychomycosis and identified by molecular and morphologic methods. C. parapsilosis ATCC 22019 and T. mentagrophytes ATCC 4439 were included as control strains.
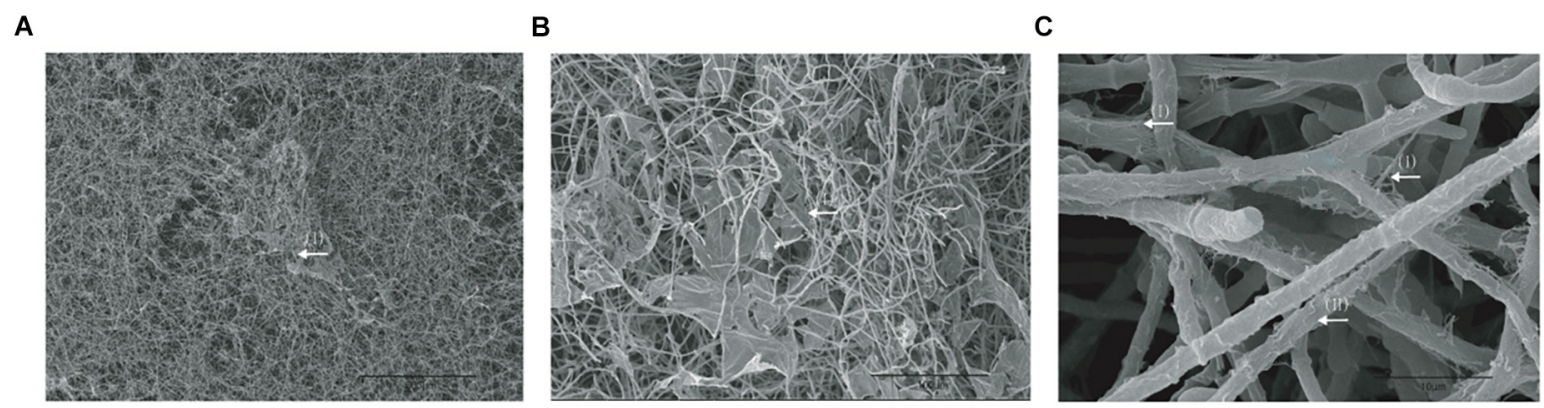

FIGURE 1 | SEM images of the biofilms of T. mentagrophytes SEM provided three-dimensional images for biofilm structural assessment, with low magnification of x100 displayed in (A) and high magnifications of x500 and x5000 displayed in (B) and (C), respectively. Two types of peculiar ECM architecture can be observed: (I) an extremely thin "blanket-like" layer covering the areas between hyphae (B); (II) very fine "mesh-like" layer wrapping the filaments of hyphae (C). 


\section{Antifungal Agents}

All antifungal drugs including terbinafine (TRB; purity $\geq 98 \%$, SIGMA), itraconazole (ITC; purity $\geq 99 \%$, SIGMA), cyclopirox (CLO; purity $\geq 99 \%$, European Pharmacopoeia Reference Standard), and fluconazole (FLU; purity $\geq 98 \%$, SIGMA) were purchased in powder form from Sigma Chemical Co., St. Louis, MO and prepared as outlined in the clinical and laboratory standards institute (CLSI) broth microdilution method M38-A2. The working concentration ranges of drugs were $0.0009785 \sim 0.5 \mu \mathrm{g} / \mathrm{ml}$ for TRB, $0.03125 \sim 16 \mu \mathrm{g} / \mathrm{ml}$ for ITC and $\mathrm{CLO}$ and $0.125 \sim 64 \mu \mathrm{g} / \mathrm{ml}$ for FLU.

\section{Biofilm Preparation in 96-Well Microtiter Plates}

Biofilm formation assay was performed in 96-well microtiter plates based on the method described by Costa-Orlandi et al. (2014) and further verified by Brilhante and Toukabri (Brilhante et al., 2017; Toukabri et al., 2018). The strains were grown on oatmeal agar (BD company) and incubated at $28^{\circ} \mathrm{C}$ for 14 days until sporulation. The inoculum was prepared by covering the cultures with $0.01 \mathrm{M}$ PBS (PH 7.2) adjusting to a final concentration of $1 \times 10^{6} \mathrm{CFU} / \mathrm{ml}$. Then, $100 \mu \mathrm{l}$ of inoculum were added to 96-well plates (Corning 3599). The plates were incubated without agitation at $37^{\circ} \mathrm{C}$ for $3 \mathrm{~h}$ for biofilm pre-adhesion. Then, the supernatant was gently removed from the wells and the cells were washed three times with 0.01M PBS (PH 7.2) for removing non-adherent cells. Following that, $100 \mu \mathrm{l}$ of RPMI 1640 medium were added and the plates were incubated at $37^{\circ} \mathrm{C}$ for $72 \mathrm{~h}$. The media were then carefully extracted without disturbing the biofilm. The 96-well plate was washed with sterile PBS for three times to remove detached spores.

\section{Scanning Electron Microscopy}

For SEM analysis, the preparation of biofilms was conducted on Thermanox coverslips (Thermo Fisher Scientific) instead of microtiter plates (Costa-Orlandi et al., 2014; de Aguiar Cordeiro et al., 2015). After $72 \mathrm{~h}$ incubation, the biofilms were fixed with $500 \mu \mathrm{l}$ of $2.5 \%$ glutaraldehyde at $4^{\circ} \mathrm{C}$ overnight. Then biofilms were washed with cacodylate buffer twice, followed by $10 \mathrm{~min}$ dehydration with ethanol at each ascending concentrations (50, $70,80,95$, and $100 \%$ ethanol) and drying for $30 \mathrm{~min}$ at $28^{\circ} \mathrm{C}$. After drying, samples were dried in $\mathrm{CO}_{2}$, coated with gold and observed in a FEI Quanta 250 scanning electron microscope (FEI, Netherlands).

\section{Colony Forming Unit Counting}

Colony forming unit is a cellular viability metric, measured by raw counts of clones growing in a standard sized Petri dish. Briefly, $200 \mu \mathrm{l}$ of sterile water was added into each well of 96-well plate after the biofilm formation, followed by vigorous washing to thoroughly suspend the biofilm cells. The suspensions were then diluted 100 times by taking $2 \mu \mathrm{l}$ of suspension diluted into $198 \mu \mathrm{l}$ sterile water, after which half of the diluted suspension was used for inoculating a SDA plate for colony counting.
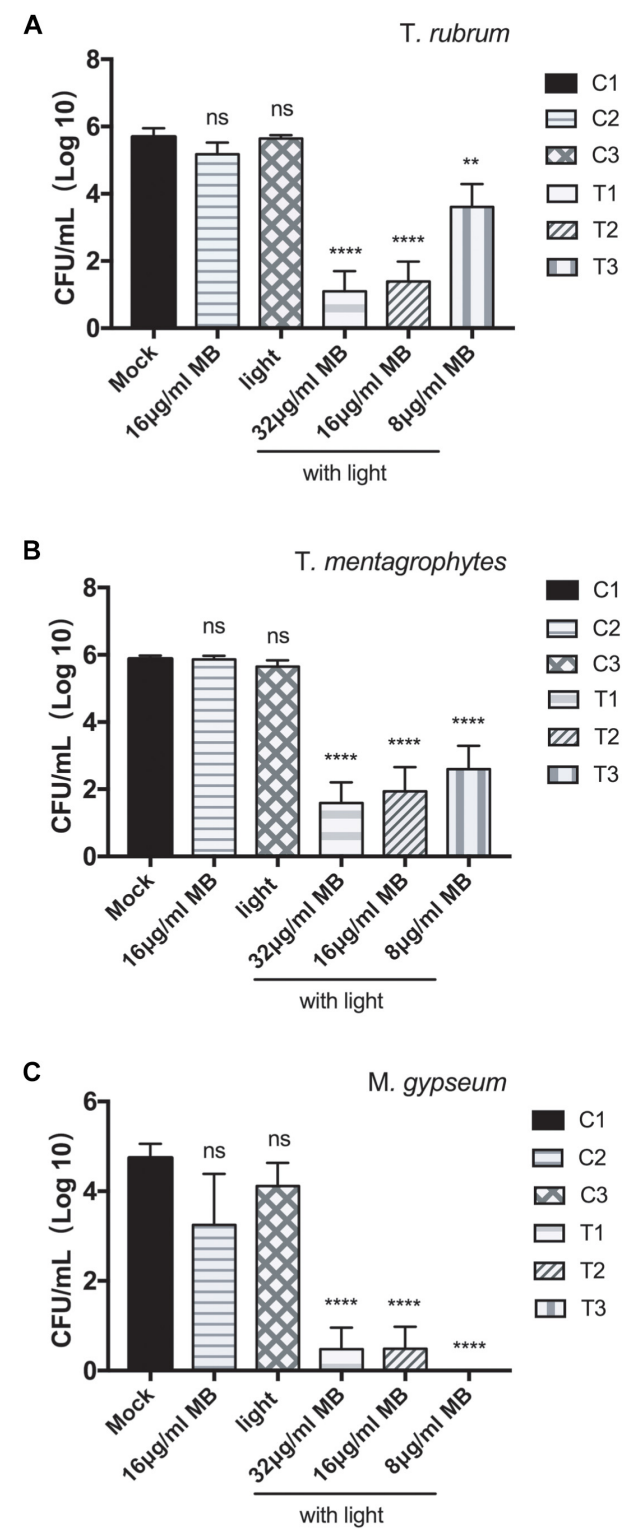

FIGURE 2 | Photodynamic inhibition on the biofilms of T. rubrum, T. mentagrophytes, and M. gypseum. CFU counting indicated the viabilities of the biofilms of T. rubrum (A), T. mentagrophytes (B), and M. gypseum (C) under the conditions: T1, photodynamic treatment with $32 \mu \mathrm{g} / \mathrm{ml}$ of methylene blue; T2, photodynamic treatment with $16 \mu \mathrm{g} / \mathrm{ml}$ of methylene blue; T3, photodynamic treatment with $8 \mu \mathrm{g} / \mathrm{ml}$ of methylene blue; $\mathrm{C} 1$, mock condition with no irradiation and no methylene blue application; C2, exposed to $16 \mu \mathrm{g} / \mathrm{ml}$ of methylene blue without irradiation; C3, exposed to irradiation with no methylene blue applied. All data were represented as the mean $\pm \mathrm{SD}$ (Two-way ANOVA, $p$ values are in comparison to the results of $\mathrm{C} 1$ mock control: * $p \leq 0.05$; ${ }^{* *} p \leq 0.01$; *** $p \leq 0.001$; **** $p \leq 0.0001$; ns $\left.p>0.05\right)$.

\section{XTT Reduction Colorimetric Assay}

A semiquantitative measure of biofilm formation was calculated by using an XTT [2,3-bis(2-methoxy-4-nitro-5-sulfo-phenyl)$2 \mathrm{H}$-tetra-zolium-5-carboxanilide] reduction assay, adapted from previous reports. XTT was prepared in a saturated solution at 
TABLE 1 | Effects of photodynamic inhibition on the biofilms of dermatophytes.

\begin{tabular}{|c|c|c|c|c|c|c|c|}
\hline Strain & & Mock (CFU/ml) & $\begin{array}{c}16 \mu \mathrm{g} / \mathrm{ml} \mathrm{M} \\
\text { (CFU/ml) }\end{array}$ & $\begin{array}{l}\text { Light } \\
\text { (CFU/ml) }\end{array}$ & $\begin{array}{c}32 \mu \mathrm{g} / \mathrm{ml} \text { MB } \\
\text { with light } \\
\text { (CFU/ml) }\end{array}$ & $\begin{array}{c}16 \mu \mathrm{g} / \mathrm{ml} \mathrm{MB} \\
\text { with light } \\
\text { (CFU/ml) }\end{array}$ & $\begin{array}{c}8 \mu \mathrm{g} / \mathrm{ml} \mathrm{MB} \\
\text { with light } \\
\text { (CFU/ml) }\end{array}$ \\
\hline \multirow[t]{6}{*}{ T. rubrum } & RCMMPU-16463 & $1.11 \times 10^{6}$ & $7.67 \times 10^{5}$ & $8.42 \times 10^{5}$ & $5 \times 10^{3}$ & $5 \times 10^{3}$ & $2.02 \times 10^{5}$ \\
\hline & RCMMPU-16355 & $9.75 \times 10^{5}$ & $5.82 \times 10^{5}$ & $7.7 \times 10^{5}$ & $6.67 \times 10^{3}$ & $5.5 \times 10^{4}$ & $2.32 \times 10^{5}$ \\
\hline & RCMMPU-41452 & $1.24 \times 10^{6}$ & $1.64 \times 10^{6}$ & $9.92 \times 10^{5}$ & 0 & $1.67 \times 10^{3}$ & $3.42 \times 10^{5}$ \\
\hline & RCMMPU-41467 & $1.3 \times 10^{6}$ & $1.33 \times 10^{6}$ & $1.18 \times 10^{6}$ & $2.83 \times 10^{5}$ & $5.88 \times 10^{5}$ & $8 \times 10^{5}$ \\
\hline & RCMMPU-16618 & $4.5 \times 10^{4}$ & $2.33 \times 10^{4}$ & $2.45 \times 10^{5}$ & 0 & 0 & $1.38 \times 10^{5}$ \\
\hline & RCMMPU-41453 & $9.35 \times 10^{5}$ & $3.25 \times 10^{5}$ & $4.33 \times 10^{5}$ & 0 & 0 & $6.67 \times 10^{3}$ \\
\hline \multirow[t]{10}{*}{ T. mentagrophytes } & RCMMPU-7240 & $1.47 \times 10^{6}$ & $1.87 \times 10^{6}$ & $1.32 \times 10^{6}$ & $1.43 \times 10^{5}$ & $2.92 \times 10^{5}$ & $4.43 \times 10^{5}$ \\
\hline & RCMMPU-5614 & $1.96 \times 10^{6}$ & $1.81 \times 10^{5}$ & $1.48 \times 10^{6}$ & $8.17 \times 10^{4}$ & $1.15 \times 10^{5}$ & $3.1 \times 10^{5}$ \\
\hline & RCMMPU-16446 & $1.21 \times 10^{6}$ & $1.13 \times 10^{6}$ & $8.52 \times 10^{5}$ & $4.17 \times 10^{4}$ & $3.93 \times 10^{5}$ & $5.53 \times 10^{5}$ \\
\hline & RCMMPU-16339 & $1.1 \times 10^{6}$ & $9.42 \times 10^{5}$ & $7.78 \times 10^{5}$ & $4 \times 10^{4}$ & $1.5 \times 10^{5}$ & $1.55 \times 10^{5}$ \\
\hline & RCMMPU-16494 & $3.1 \times 10^{5}$ & $6.07 \times 10^{5}$ & $3.77 \times 10^{5}$ & 0 & 0 & 0 \\
\hline & RCMMPU-16077 & $7.1 \times 10^{5}$ & $5.53 \times 10^{5}$ & $7.85 \times 10^{5}$ & 0 & 0 & 0 \\
\hline & MYA-4439 & $1.6 \times 10^{6}$ & $1.64 \times 10^{6}$ & $1.09 \times 10^{6}$ & $3.83 \times 10^{4}$ & $3.87 \times 10^{5}$ & $4.35 \times 10^{5}$ \\
\hline & RCMMPU-8395 & $6.95 \times 10^{5}$ & $6.33 \times 10^{5}$ & $8.52 \times 10^{5}$ & 0 & 0 & $1 \times 10^{4}$ \\
\hline & RCMMPU-8396 & $3.08 \times 10^{5}$ & $2.15 \times 10^{5}$ & $6.07 \times 10^{5}$ & 0 & 0 & 0 \\
\hline & RCMMPU-8397 & $3.62 \times 10^{5}$ & $2.12 \times 10^{5}$ & $3.3 \times 10^{5}$ & 0 & 0 & $2.87 \times 10^{5}$ \\
\hline \multirow[t]{3}{*}{ M. gypseum } & RCMMPU-13789 & $4.67 \times 10^{4}$ & $1.67 \times 10^{3}$ & $5.5 \times 10^{4}$ & 0 & 0 & 0 \\
\hline & RCMMPU-8305 & $2 \times 10^{4}$ & $7.67 \times 10^{4}$ & $3.5 \times 10^{4}$ & $6.67 \times 10^{3}$ & $8.33 \times 10^{3}$ & 0 \\
\hline & RCMMPU-8825 & $2.15 \times 10^{5}$ & $1.88 \times 10^{5}$ & $1.2 \times 10^{5}$ & 0 & 0 & 0 \\
\hline
\end{tabular}

Data are mean values from three replicate experiments.

$0.5 \mathrm{~g} /$ liter in Ringer's lactate. The solution was filter sterilized through a $0.22-\mu \mathrm{m}$-pore-size filter, aliquoted, and stored at $-70^{\circ} \mathrm{C}$. Prior to each assay, an aliquot of stock XTT was thawed, and menadione (Sigma; $10 \mathrm{mM}$ prepared in acetone) was added to a final concentration of $1 \mu \mathrm{M}$. A $100 \mu \mathrm{l}$ aliquot of the XTT-menadione solution was then added to each prewashed biofilm and to control wells (for the measurement of background XTT-reduction levels). The plates were then incubated in the dark for up to $2 \mathrm{~h}$ at $37^{\circ} \mathrm{C}$. The activity of the fungal mitochondrial dehydrogenase reduces the tetrazolium salt XTT to formazan salts, resulting in a colorimetric change that correlates with cell viability. The colorimetric change was measured using an ELISA reader (Microplate Reader iMarkTM; BIO-RAD) at $490 \mathrm{~nm}$. In all experiments, RPMI 1640 medium free of biofilm formation was included as a negative control (Mowat et al., 2007; Pitangui et al., 2012).

\section{Photodynamic Treatment}

The PDI technique with modifications in the volume used, the incubation time, and the concentrations of methylene blue was described by Lyon et al. (2013). The methylene blue was tested at concentrations of $32 \mu \mathrm{g} / \mathrm{ml}$ (T1), $16 \mu \mathrm{g} / \mathrm{ml}$ (T2) and $8 \mu \mathrm{g} / \mathrm{ml}$ (T3), with $100 \mu \mathrm{l}$ of each concentration added into 96 -well plates containing biofilms. After incubation in dark for $3 \mathrm{~h}$ at $37^{\circ} \mathrm{C}$, the biofilms were irradiated using a LED with an irradiance of $100 \mathrm{~mW} / \mathrm{cm}^{2}$ at a wavelength of $635 \pm 10 \mathrm{~nm}$ and a distance of $1 \mathrm{~cm}$ for $600 \mathrm{~s}\left(60 \mathrm{~J} / \mathrm{cm}^{2}\right)$. Control conditions were conducted as biofilms in PBS without irradiation (C1), biofilms with methylene blue $(16 \mu \mathrm{g} / \mathrm{ml})$ and without irradiation (C2), biofilms in PBS, and irradiated (C3).

\section{SMICs Determination}

The values of SMICs were experimentally determined in this study using XTT-reduction colorimetric assay. The working concentrations of TRB, ITC, CLO, and FLU were prepared by a series of twofold dilutions (dilution range, $0.5-0.0009785 \mu \mathrm{g} / \mathrm{ml}$ for TRB; 16 to $0.03125 \mu \mathrm{g} / \mathrm{ml}$ for ITC and CLO; 64 to $0.125 \mu \mathrm{g} / \mathrm{ml}$ for FLU). The SMIC80s of TRB, ITC, CLO, and FLU were defined as the concentration at which $80 \%$ decrease in optical density would be detected in comparison to the mock controls in the absence of antimicrobial agents (Pierce et al., 2008). All tests were performed in triplicate.

\section{Statistical Analysis}

Data were presented as the mean \pm SD and analyzed with PRISM software package version 7.0 (XLSTAT Addinsoft, Paris, France). Three independent experiments were performed for all measurements. The differences between two groups were analyzed with Student's $t$-test. Two-way ANOVA analysis was used to determine statistical differences among multiple groups. $p<0.05$ was considered as statistical significance.

\section{RESULTS}

\section{Biofilm Morphology}

Biofilm formation using the strain of T. mentagrophytes 7240 islolated from clinical specimen was prepared on coverslip according to the method described by Costa-Orlandi et al. (2014). SEM providing three-dimensional images for in-depth structural assessment revealed that T. mentagrophytes 7240 
produced noticeably robust biofilms with branched hyphae forming a mycelial network (Figure 1A), firmly attached to the coverslips. In particular, two types of peculiar extracellular matrix (ECM) architecture could be observed: (i) an extremely thin "blanket-like" layer covering the areas between hyphae (Figure 1B); (ii) very fine "mesh-like" layer wrapping the filaments of hyphae (Figure 1C). The biofilm morphology of high resolution and magnification was investigated and imaged by SEM technique to confirm the biofilm-formation in this study and the SEM images obtained are similar to those reported previously (Brilhante et al., 2017; Vila et al., 2017; Guzel Tunccan et al., 2018).

\section{aPDT Reducing the Viability of the Biofilms of Dermatophytes}

The aPDT with LED (InGaAlP, $100 \mathrm{~mW} / \mathrm{cm}^{2}$ ) exhibited CFU reduction by $2.0 \log _{10}, 4.3 \log _{10}$, and $4.6 \log _{10}$ against the biofilms formed by $T$. rubrum at the concentrations of $\mathrm{MB}$ 8, 16, and $32 \mu \mathrm{g} / \mathrm{ml}$, respectively (Figure 2 and Table 1), demonstrating photodynamic inactivation in $\mathrm{MB}$ concentration dependent manner. The biofilms of T. mentagrophytes displayed the same pattern as to that of T. rubrum, with the CFU reductions at $3.3 \log _{10}, 4.0 \log _{10}$, and $4.3 \log _{10}$, accordingly. Interestingly, in contrast to T. rubrum and T. mentagrophytes, the CFU reduction of M. gypseum was more efficient at the concentration of $\mathrm{MB}$ $8 \mu \mathrm{g} / \mathrm{ml}\left(4.7 \log _{10}\right)$ than that of $32 \mu \mathrm{g} / \mathrm{ml}$ or $16 \mu \mathrm{g} / \mathrm{ml}\left(4.26 \log _{10}\right.$ and $4.25 \log _{10}$, respectively). Such observation was probably due to generally high susceptibility of $M$. gypseum to aPDT and fewer strains have been tested in this study. Subsequently, no significant differences in CFU reductions were observed at the chosen concentrations of MB for M. gypseum. However, the efficiencies of aPDT against the biofilms of dermatophytes were lower than that of the biofilms formed by Fusarium spp., previously reported as $5.6 \log _{10}$ in reduction with the same aPDT regimen (Gao et al., 2016), suggesting the biofilms of dermatophytes may be relatively more resistant to aPDT than other fungal pathogens associated biofilms. Nevertheless, with the CFU reductions ranging from 2 $\log _{10}$ to $4 \log _{10}$, aPDT proved to be a highly effective approach against the biofilms of dermatophytes in vitro.

\section{aPDT Increasing the Susceptibilities of Biofilms to Conventional Antimicrobial Agents}

SMIC ranges of terbinafine (TRB), itraconazole (ITC), cyclopirox (CLO), and fluconazole (FLU) against biofilms with or without aPDT (T1 regimen) were summarized in Figure 3 and Table 2. The susceptibilities of $T$. rubrum, T. mentagrophytes, and M. gypseum biofilms to these antifungal agents were variable, but TRB was consistently more efficient against fungal growth comparing to ITC, CLO, and FLE in all three species tested. The biofilms that were subjected to aPDT exhibited significant reductions in SMIC80 when compared with aPDT untreated groups, indicating that the treatment of aPDT effectively increased the susceptibilities of T. rubrum, T. mentagrophytes and $M$. gypseum to these conventional antimicrobial drugs. Furthermore, aPDT exerted comparable effects on increasing the susceptibility of T. rubrum, T. mentagrophytes to TRB, ITC, CLO,

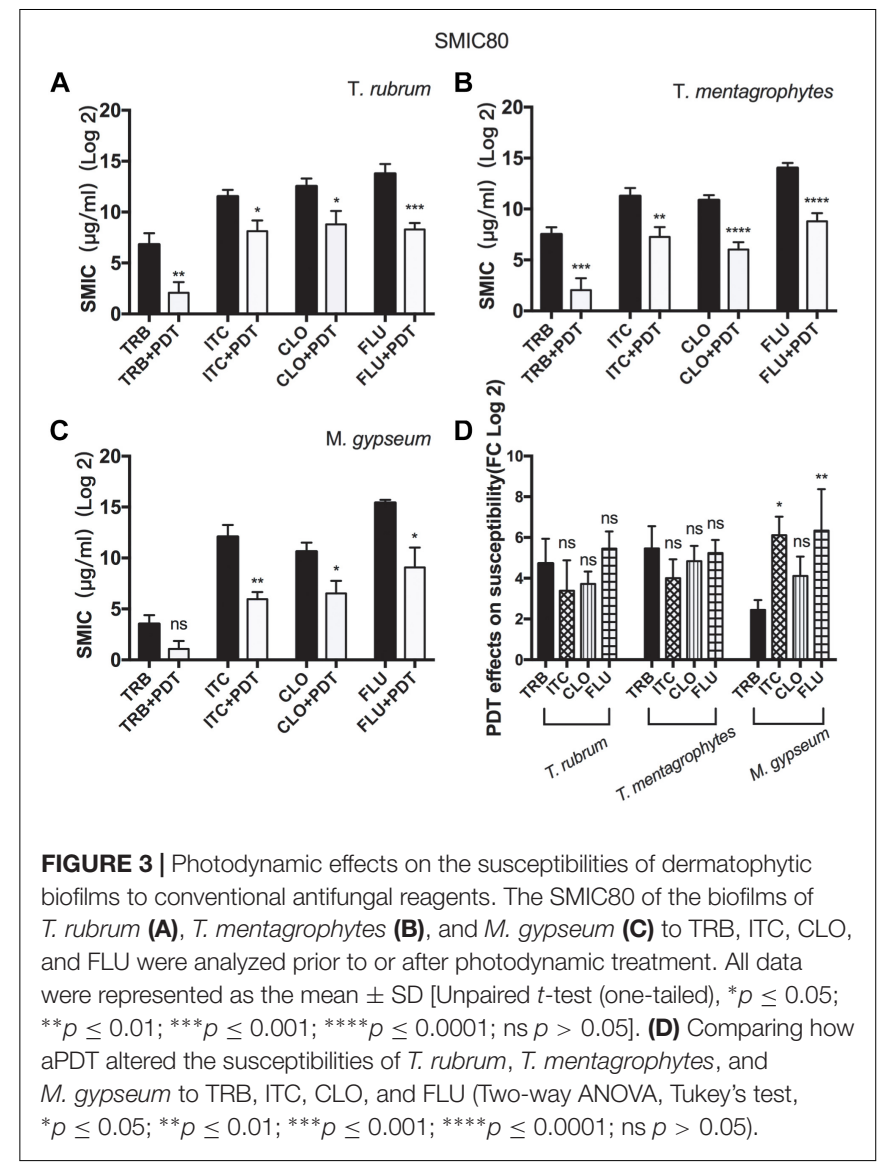

and FLU as shown in the Figure 3D. In contrast, the susceptibility of $M$. gypseum to TRB after aPDT was less affected, where the SMIC80 of TRB without aPDT was just four times higher than that with aPDT, much lower than 64-fold increase observed with ITC and FLU.

\section{Obliteration of Biofilm Resulted From Photodynamic Therapy}

To investigate the morphological alteration of dermatophyte biofilm after aPDT (T1 regimen), SEM images of $M$. gypseum biofilm were obtained following the photodynamic treatment. As shown in the Figure 4, comparing to aPDT untreated specimen (Figure 4A) in which dense entangled hyphae exhibited regular morphology with uniform diameter and smooth surfaces as well as the characteristic "blanket-like" membrane and fine "mesh-like" wrapping layer were present, the mycelia of M. gypseum biofilm after aPDT treatment were fractured and shattered with raptured hyphae and fragmented "blanket-like" membranes (Figures 4B-D).

\section{DISCUSSION}

Onychomycosis is the most common nail infective disorder (Piraccini and Alessandrini, 2015) and is caused primarily by anthropophilic dermatophytes, in particular by Trichophyton rubrum, followed by Trichophyton mentagrophytes var. 
TABLE 2 | Photodynamic effects on the SMIC80 of dermatophytic biofilms.

\begin{tabular}{|c|c|c|c|c|c|c|c|c|c|}
\hline \multirow[t]{3}{*}{ Strain } & & \multicolumn{8}{|c|}{ SMIC80 ( $\mu \mathrm{g} / \mathrm{ml})$} \\
\hline & & \multicolumn{2}{|c|}{ TRB } & \multicolumn{2}{|c|}{ ITC } & \multicolumn{2}{|c|}{ CLO } & \multicolumn{2}{|c|}{ FLU } \\
\hline & & -PDT & +PDT & -PDT & +PDT & -PDT & +PDT & -PDT & +PDT \\
\hline \multirow[t]{6}{*}{ T. rubrum } & RCMMPU-16463 & 0.146 & 0.022 & 3.000 & 0.042 & 16.000 & 6.667 & 64.000 & 0.708 \\
\hline & RCMMPU-16355 & 0.500 & 0.011 & 6.333 & 0.729 & 1.000 & 0.031 & 1.417 & 0.125 \\
\hline & RCMMPU-41452 & 0.012 & 0.006 & 1.833 & 4.000 & 13.333 & 1.333 & 48.000 & 3.333 \\
\hline & RCMMPU-41467 & 0.500 & 0.336 & 13.333 & 0.042 & 1.333 & 0.031 & 53.333 & 0.125 \\
\hline & RCMMPU-16618 & 0.500 & 0.001 & 9.333 & 2.010 & 12.000 & 1.677 & 22.750 & 0.250 \\
\hline & RCMMPU-41453 & 0.029 & 0.001 & 5.510 & 5.427 & 16.000 & 2.000 & 42.833 & 0.375 \\
\hline \multirow[t]{10}{*}{ T. mentagrophytes } & RCMMPU-7240 & 0.375 & 0.001 & 16.000 & 16.000 & 1.000 & 0.031 & 64.000 & 13.500 \\
\hline & RCMMPU-5614 & 0.500 & 0.001 & 16.000 & 5.750 & 1.000 & 0.031 & 25.333 & 0.125 \\
\hline & RCMMPU-16446 & 0.417 & 0.001 & 6.167 & 0.031 & 0.667 & 0.031 & 10.833 & 0.125 \\
\hline & RCMMPU-16339 & 0.500 & 0.002 & 6.833 & 0.385 & 16.000 & 0.031 & 3.667 & 0.125 \\
\hline & RCMMPU-16494 & 0.500 & 0.500 & 1.396 & 5.354 & 1.042 & 0.031 & 32.000 & 21.833 \\
\hline & RCMMPU-16077 & 0.500 & 0.500 & 6.167 & 5.354 & 8.667 & 0.031 & 48.000 & 42.708 \\
\hline & MYA-4439 & 0.500 & 0.011 & 11.000 & 0.031 & 1.750 & 0.031 & 43.333 & 0.458 \\
\hline & RCMMPU-8395 & 0.073 & 0.001 & 16.000 & 0.031 & 5.333 & 2.667 & 16.000 & 0.125 \\
\hline & RCMMPU-8396 & 0.027 & 0.001 & 0.229 & 0.031 & 2.167 & 0.042 & 64.000 & 0.125 \\
\hline & RCMMPU-8397 & 0.014 & 0.001 & 0.333 & 0.031 & 1.667 & 1.344 & 13.333 & 0.250 \\
\hline \multirow[t]{3}{*}{ M. gypseum } & RCMMPU-13789 & 0.172 & 0.084 & 16.000 & 0.698 & 6.708 & 0.031 & 42.667 & 24.333 \\
\hline & RCMMPU-8305 & 0.013 & 0.001 & 10.833 & 0.031 & 0.875 & 0.052 & 32.000 & 0.167 \\
\hline & RCMMPU-8825 & 0.005 & 0.001 & 5.542 & 0.063 & 8.167 & 1.021 & 64.000 & 0.125 \\
\hline
\end{tabular}

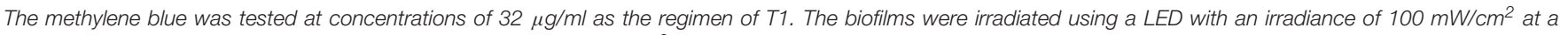
wavelength of $635 \pm 10 \mathrm{~nm}$ and a distance of $1 \mathrm{~cm}$ for $600 \mathrm{~s}\left(60 \mathrm{~J} / \mathrm{cm}^{2}\right)$. Data are mean values from three replicate experiments.

A

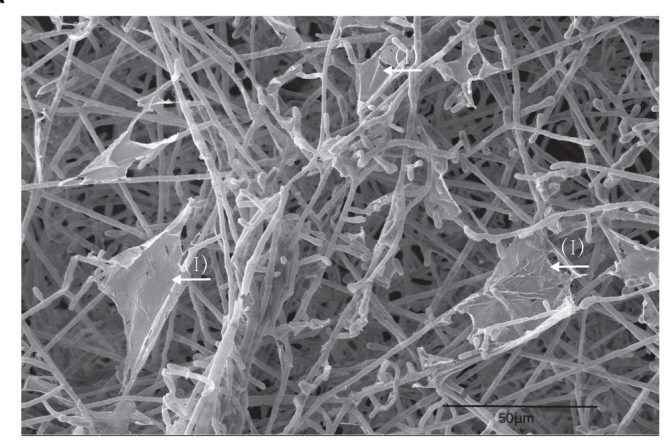

c

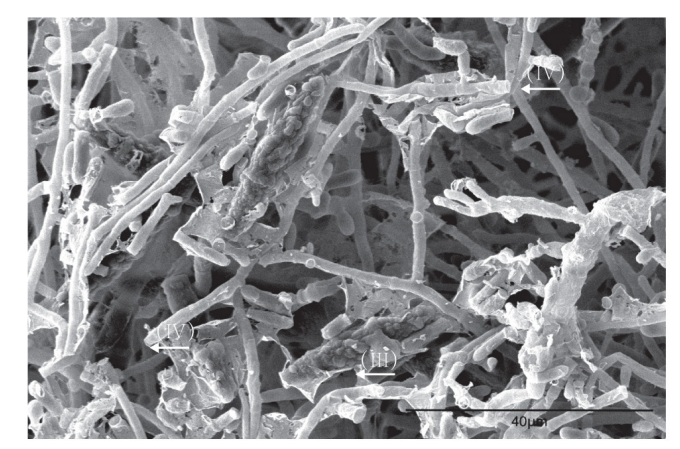

B

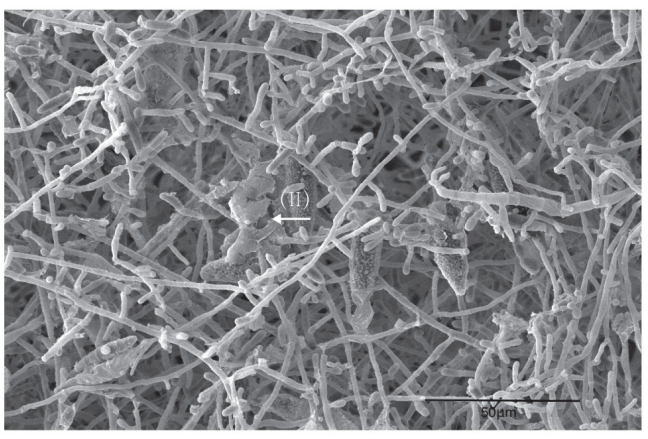

D

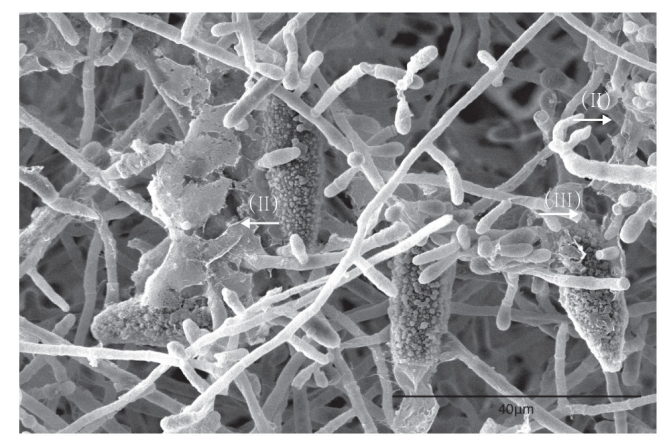

FIGURE 4 | SEM images of the bioflms of M. gypseum after photodynamic treatment. (A) M. gypseum not subjected to photodynamic treatment. (B-D) M. gypseum subjected to photodynamic treatment. (I) Formation of a relatively complete membrane-like structure. (II) Biofilms appeared to have a "hole" in their surface, with a tearing appearance. (III) Perforated ECM surrounded the macroconidia. (IV) Mycelia were fractured, sections of hyphae were broken. 
interdigitale (Faergemann and Baran, 2003). The nondermatophyte molds, such as Fusarium spp., Acremonium spp., Alternaria spp., Scopulariopsis brevicaulis, Aspergillus spp., can also be involved in the pathogenesis with estimated 10\% prevalence worldwide (Gupta and Nakrieko, 2014; Gasser et al., 2016; Gupta et al., 2016; Motamedi et al., 2016). Yeasts, like Candida albicans and Candida parapsilosis, represent the third cause of nail fungal infection, but only occurring when predisposing factors are present, mainly immunosuppression, and diabetes (Arrua et al., 2015; Gasser et al., 2016).

Developing novel therapeutic approach against the biofilms of dermatophytes implicated in recalcitrant onychomycosis presents a pressing need in the clinical management, especially the onychopathic condition with dermatophytoma (Sigurgeirsson, 2010). Initially established as a successful modality for malignancies and age-related macular degeneration (Dougherty et al., 1978; Orenstein et al., 1996), photodynamic inactivation has been shown as an effective alternative strategy for combating biofilms. The antimicrobial effects of aPDT have been observed on bacterial, non-dermatophytic, and yeast biofilms in vitro as well as in vivo using various animal models (Friedberg et al., 2001; Giroldo et al., 2009; Lyon et al., 2011; Soares et al., 2011; Takahashi et al., 2014; da Silva et al., 2018). However, the aPDT effect on dermatophytic biofilms has been less investigated due to the lack of reliable models. Fortunately, Costa-Orlandi et al. have recently successfully established the procedure to in vitro form the biofilms of dermatophytes using the stains of T. rubrum ATCC 28189 and T. mentagrophytes ATCC 11481 within $72 \mathrm{~h}$, providing a valuable in vitro model to facilitate the investigation of photodynamic effect on dermatophytic biofilms (Costa-Orlandi et al., 2014). In addition to ATCC strains, the dermatophytic isolates obtained from clinical onychomycosis specimens ranging from T. rubrum, T. mentagrophytes to M. gypseum were examined and selected for their capability of biofilm-forming in vitro in our study. Due to the generally low sporulation of T. rubrum, only 6 out of 70 initial clinical isolates were identified capable of forming biofilm after $72 \mathrm{~h}$ of cultivation. Ultimately, six strains of T. rubrum, ten strains of T. mentagrophytes and three strains of M. gypseum capable of biofilm formation were subsequently subjected to aPDT based assays, enabling us to gain an in-depth insight into the application of aPDT against dermatophytic biofilms implicated in clinical onychopathic infections.

Photodynamic inactivation of aPDT requires the application of photosensitizer (PS) and subsequent irradiation with visible light corresponding to the specific absorption wavelength of photosensitizer (Castano et al., 2005; Plaetzer et al., 2009). A variety of PSs have been previously used in antifungal photodynamic inactivation, including $\mathrm{MB}$, toluidine blue, 5-aminolevulinic acid, and so on (Cormick et al., 2009; CalzavaraPinton et al., 2012; Dai et al., 2012). The photosensitizer MB used in our investigation has an absorption wavelength over $600 \mathrm{~nm}$, which has been shown capable of exerting substantial reduction on the biofilms of dermatophytes tested. However, T. rubrum appeared more resistant than T. mentagrophytes and M. gypseum and the $\mathrm{MB}$ concentration dependence was more evident in $T$. rubrum than that of $T$. mentagrophytes and $M$. gypseum, presumably due to T. rubrum being equipped with abundant red pigments that may interfere the absorption of MB's chromophore.

The effect of aPDT on the susceptibility of dermatophytic biofilms to clinically applied antifungal agents was examined and the biofilms subjected to aPDT exhibited significant reductions in SMIC80, meaning aPDT effectively increased the susceptibilities of T. rubrum, T. mentagrophytes and M. gypseum to these conventional antimicrobial drugs, including terbinafine, itraconazole, cyclopirox, and fluconazole. The mechanism underlying aPDT-induced disruption rendering biofilms more susceptible could be multi-factorial, involving photodynamic action targeting multiple cellular components, such as fractionating plasma membrane, triggering ion imbalance leading to intolerable changes in osmotic pressure and $\mathrm{pH}$, and DNA breaking. The observed sensitization of dermatophytes to the antifungal agents resulted from the decreased biofilm viability in this study, however, in the future, more investigation with sub-lethal dose of aPDT could be conducted to have a better understanding of how different levels of oxidative and nitrosative stresses affecting the susceptibility of dermatophytic biofilms to antimicrobials and to facilitate the optimization of combination therapies.

In conclusion, our results suggest that photodynamic approaches hold great promise for combating the biofilm of dermatophytes involved in onychomycosis. In vitro photodynamic treatment with methylene blue and LED was found to be highly efficient in inactivating dermatophytic biofilms of T. rubrum, T. mentagrophytes, and M. gypseum. When aPDT applied alongside antifungal agents, it has the potential to reduce drug dosages, drug toxicity, and treatment times. Further investigation is needed to address if such efficacy could be ultimately obtained in vivo and it is important to optimize treatment protocols to cope with constrained drug permeation and light attenuation through nail plates in human studies.

\section{AUTHOR CONTRIBUTIONS}

BC, YS, and JGZ conceived and designed the study. BC, JYZ, RC, and $\mathrm{XZ}$ performed all the experiments. $\mathrm{BC}$ and $\mathrm{XW}$ analyzed the data and wrote the manuscript. JGZ, LZ, and XW provided the general guidance and revised the manuscript.

\section{FUNDING}

This work was sponsored by the National Natural Science Foundation of China (81874240), Natural Science Foundation of Shanghai (16ZR1432400), and the Clinical Medicine Center Construction Program of Fuzhou (Grant No. 2018080309).

\section{ACKNOWLEDGMENTS}

We thank Prof. Ruoyu Li and Zhe Wan from Peking University First Hospital, Research Center for Medical Mycology for kindly providing us with the isolates studied. Our appreciation also goes to Prof. Li Fushan and Zhongwei Xu from Fuzhou University for their support in SEM study. 


\section{REFERENCES}

Al-Ahmad, A., Walankiewicz, A., Hellwig, E., Follo, M., Tennert, C., Wittmer, A., et al. (2016). Photoinactivation using visible light plus water-filtered infrared-A (vis+wIRA) and chlorine e6 (Ce6) eradicates planktonic periodontal pathogens and subgingival biofilms. Front. Microbiol. 7:1900. doi: 10.3389/fmicb.2016. 01900

Al-Fattani, M. A., and Douglas, L. J. (2006). Biofilm matrix of Candida albicans and Candida tropicalis: chemical composition and role in drug resistance. J. Med. Microbiol. 55(Pt 8), 999-1008. doi: 10.1099/jmm.0.46569-0

Ali, I., Satti, N. K., Dutt, P., Prasad, R., and Khan, I. A. (2016). Hydroxychavicol: a phytochemical targeting cutaneous fungal infections. Sci. Rep. 6:37867. doi: $10.1038 /$ srep37867

Alves, E., Faustino, M. A., Neves, M. G., Cunha, A., Tome, J., and Almeida, A. (2014). An insight on bacterial cellular targets of photodynamic inactivation. Future Med. Chem. 6, 141-164. doi: 10.4155/fmc.13.211

Arrese, J. E., and Pierard, G. E. (2003). Treatment failures and relapses in onychomycosis: a stubborn clinical problem. Dermatology 207, 255-260. doi: $10.1159 / 000073086$

Arrua, J. M., Rodrigues, L. A., Pereira, F. O., and Lima, E. O. (2015). Prevalence of Candida tropicalis and Candida krusei in onychomycosis in Joao Pessoa, Paraiba, Brazil from 1999 to 2010. An. Acad. Bras. Cienc. 87, 1819-1822. doi: 10.1590/0001-3765201520130418

Baltazar, L. M., Ray, A., Santos, D. A., Cisalpino, P. S., Friedman, A. J., and Nosanchuk, J. D. (2015). Antimicrobial photodynamic therapy: an effective alternative approach to control fungal infections. Front. Microbiol. 6:202. doi: $10.3389 /$ fmicb. 2015.00202

Baran, R., Sigurgeirsson, B., de Berker, D., Kaufmann, R., Lecha, M., Faergemann, J., et al. (2007). A multicentre, randomized, controlled study of the efficacy, safety and cost-effectiveness of a combination therapy with amorolfine nail lacquer and oral terbinafine compared with oral terbinafine alone for the treatment of onychomycosis with matrix involvement. Br. J. Dermatol. 157, 149-157. doi: 10.1111/j.1365-2133.2007.07974.x

Beirao, S., Fernandes, S., Coelho, J., Faustino, M. A., Tome, J. P., Neves, M. G., et al. (2014). Photodynamic inactivation of bacterial and yeast biofilms with a cationic porphyrin. Photochem. Photobiol. 90, 1387-1396. doi: 10.1111/php. 12331

Brilhante, R. S. N., Correia, E. E. M., Guedes, G. M. M., Pereira, V. S., Oliveira, J. S., Bandeira, S. P., et al. (2017). Quantitative and structural analyses of the in vitro and ex vivo biofilm-forming ability of dermatophytes. J. Med. Microbiol. 66, 1045-1052. doi: 10.1099/jmm.0.000528

Burkhart, C. N., Burkhart, C. G., and Gupta, A. K. (2002). Dermatophytoma: recalcitrance to treatment because of existence of fungal biofilm. J. Am. Acad. Dermatol. 47, 629-631. doi: 10.1067/mjd.2002. 124699

Calzavara-Pinton, P., Rossi, M. T., Sala, R., and Venturini, M. (2012). Photodynamic antifungal chemotherapy. Photochem. Photobiol. 88, 512-522. doi: 10.1111/j.1751-1097.2012.01107.x

Carvalho, M. L., Pinto, A. P., Raniero, L. J., and Costa, M. S. (2018). Biofilm formation by Candida albicans is inhibited by photodynamic antimicrobial chemotherapy (PACT), using chlorin e6: increase in both ROS production and membrane permeability. Lasers Med. Sci. 33, 647-653. doi: 10.1007/s10103017-2344-1

Castano, A. P., Demidova, T. N., and Hamblin, M. R. (2005). Mechanisms in photodynamic therapy: part two-cellular signaling, cell metabolism and modes of cell death. Photodiagnosis Photodyn. Ther. 2, 1-23. doi: 10.1016/S15721000(05)00030-X

Ceri, H., Olson, M., Morck, D., Storey, D., Read, R., Buret, A., et al. (2001). The MBEC assay system: multiple equivalent biofilms for antibiotic and biocide susceptibility testing. Methods Enzymol. 337, 377-385. doi: 10.1016/s00766879(01)37026-x

Cieplik, F., Deng, D., Crielaard, W., Buchalla, W., Hellwig, E., Al-Ahmad, A., et al. (2018). Antimicrobial photodynamic therapy - what we know and what we don't. Crit. Rev. Microbiol. 44, 571-589. doi: 10.1080/1040841X.2018.1467876

Cieplik, F., Tabenski, L., Buchalla, W., and Maisch, T. (2014). Antimicrobial photodynamic therapy for inactivation of biofilms formed by oral key pathogens. Front. Microbiol. 5:405. doi: 10.3389/fmicb.2014.00405
Cormick, M. P., Alvarez, M. G., Rovera, M., and Durantini, E. N. (2009) Photodynamic inactivation of Candida albicans sensitized by tri- and tetracationic porphyrin derivatives. Eur. J. Med. Chem. 44, 1592-1599. doi: 10.1016/ j.ejmech.2008.07.026

Costa-Orlandi, C. B., Sardi, J. C., Santos, C. T., Fusco-Almeida, A. M., and MendesGiannini, M. J. (2014). In vitro characterization of Trichophyton rubrum and T. mentagrophytes biofilms. Biofouling 30, 719-727. doi: 10.1080/08927014. 2014.919282

da Silva, B. G. M., Carvalho, M. L., Rosseti, I. B., Zamuner, S., and Costa, M. S. (2018). Photodynamic antimicrobial chemotherapy (PACT) using toluidine blue inhibits both growth and biofilm formation by Candida krusei. Lasers Med. Sci. 33, 983-990. doi: 10.1007/s10103-017-2428-y

Dai, T., Fuchs, B. B., Coleman, J. J., Prates, R. A., Astrakas, C., St Denis, T. G., et al. (2012). Concepts and principles of photodynamic therapy as an alternative antifungal discovery platform. Front. Microbiol. 3:120. doi: 10.3389/fmicb.2012. 00120

Dai, T., Huang, Y. Y., and Hamblin, M. R. (2009). Photodynamic therapy for localized infections-state of the art. Photodiagnosis Photodyn. Ther. 6, 170-188. doi: 10.1016/j.pdpdt.2009.10.008

de Aguiar Cordeiro, R., Serpa, R., Flavia Uchoa Alexandre, C., de Farias Marques, F. J., Vladia Silva de Melo, C., da Silva Franco, J., et al. (2015). Trichosporon inkin biofilms produce extracellular proteases and exhibit resistance to antifungals. J. Med. Microbiol. 64, 1277-1286. doi: 10.1099/jmm.0.000159

Donlan, R. M., and Costerton, J. W. (2002). Biofilms: survival mechanisms of clinically relevant microorganisms. Clin. Microbiol. Rev. 15, 167-193. doi: $10.1128 / \mathrm{cmr} \cdot 15.2 .167-193.2002$

Dougherty, T. J., Kaufman, J. E., Goldfarb, A., Weishaupt, K. R., Boyle, D., and Mittleman, A. (1978). Photoradiation therapy for the treatment of malignant tumors. Cancer Res. 38, 2628-2635.

Evans, E. G., and Sigurgeirsson, B. (1999). Double blind, randomised study of continuous terbinafine compared with intermittent itraconazole in treatment of toenail onychomycosis. The LION Study Group. BMJ 318, 1031-1035. doi: 10.1136/bmj.318.7190.1031

Faergemann, J., and Baran, R. (2003). Epidemiology, clinical presentation and diagnosis of onychomycosis. Br. J. Dermatol. 149(Suppl. 65), 1-4. doi: 10.1046/ j.1365-2133.149.s65.4.x

Friedberg, J. S., Skema, C., Baum, E. D., Burdick, J., Vinogradov, S. A., Wilson, D. F., et al. (2001). In vitro effects of photodynamic therapy on Aspergillus fumigatus. J. Antimicrob. Chemother. 48, 105-107. doi: 10.1093/jac/48.1.105

Gao, L., Jiang, S., Sun, Y., Deng, M., Wu, Q., Li, M., et al. (2016). Evaluation of the effects of photodynamic therapy alone and combined with standard antifungal therapy on planktonic cells and biofilms of Fusarium spp. and Exophiala spp. Front. Microbiol. 7:617. doi: 10.3389/fmicb.2016. 00617

Gasser, J., Pagani, E., Vittadello, F., Nobile, C., Zampieri, P., and Eisendle, K. (2016). Frequency, type and treatment of fungal pathogens in toenail onychomycosis in the central Alpine region of South Tyrol, northern Italy - a 10-year retrospective study from 2004 to 2013. Mycoses 59, 760-764. doi: 10.1111/myc. 12528

Gilaberte, Y., Aspiroz, C., Martes, M. P., Alcalde, V., Espinel-Ingroff, A., and Rezusta, A. (2011). Treatment of refractory fingernail onychomycosis caused by nondermatophyte molds with methylaminolevulinate photodynamic therapy. J. Am. Acad. Dermatol. 65, 669-671. doi: 10.1016/j.jaad.2010. 06.008

Giroldo, L. M., Felipe, M. P., de Oliveira, M. A., Munin, E., Alves, L. P., and Costa, M. S. (2009). Photodynamic antimicrobial chemotherapy (PACT) with methylene blue increases membrane permeability in Candida albicans. Lasers Med. Sci. 24, 109-112. doi: 10.1007/s10103-007-0530-2

Gupta, A. K., Gupta, G., Jain, H. C., Lynde, C. W., Foley, K. A., Daigle, D., et al. (2016). The prevalence of unsuspected onychomycosis and its causative organisms in a multicentre Canadian sample of 30000 patients visiting physicians' offices. J. Eur. Acad. Dermatol. Venereol. 30, 1567-1572. doi: 10. $1111 /$ jdv.13677

Gupta, A. K., and Nakrieko, K. A. (2014). Molecular determination of mixed infections of dermatophytes and nondermatophyte molds in individuals with onychomycosis. J. Am. Podiatr. Med. Assoc. 104, 330-336. doi: 10.7547/00030538-104.4.330 
Gupta, A. K., Ryder, J. E., and Johnson, A. M. (2004). Cumulative meta-analysis of systemic antifungal agents for the treatment of onychomycosis. Br. J. Dermatol. 150, 537-544. doi: 10.1046/j.1365-2133.2003.05728.x

Gupta, A. K., Versteeg, S. G., and Shear, N. H. (2017). Onychomycosis in the 21st century: an update on diagnosis, epidemiology, and treatment. J. Cutan. Med. Surg. 21, 525-539. doi: 10.1177/1203475417716362

Guzel Tunccan, O., Kalkanci, A., Unal, E. A., Abdulmajed, O., Erdogan, M., Dizbay, M., et al. (2018). The in vitro effect of antimicrobial photodynamic therapy on Candida and Staphylococcus biofilms. Turk. J. Med. Sci. 48, 873-879. doi: 10.3906/sag-1803-44

Hamblin, M. R., and Hasan, T. (2004). Photodynamic therapy: a new antimicrobial approach to infectious disease? Photochem. Photobiol. Sci. 3, 436-450. doi: 10.1039/b311900a

Hawser, S. P., and Douglas, L. J. (1995). Resistance of Candida albicans biofilms to antifungal agents in vitro. Antimicrob. Agents Chemother. 39, 2128-2131. doi: $10.1128 /$ aac.39.9.2128

Junqueira, J. C., Jorge, A. O., Barbosa, J. O., Rossoni, R. D., Vilela, S. F., Costa, A. C., et al. (2012). Photodynamic inactivation of biofilms formed by Candida spp., Trichosporon mucoides, and Kodamaea ohmeri by cationic nanoemulsion of zinc 2,9,16,23-tetrakis(phenylthio)-29H, 31H-phthalocyanine ( $\mathrm{ZnPc}$ ). Lasers Med. Sci. 27, 1205-1212. doi: 10.1007/s10103-012-1050-2

Lyon, J. P., Moreira, L. M., de Carvalho, V. S., dos Santos, F. V., de Lima, C. J., and de Resende, M. A. (2013). In vitro photodynamic therapy against Foncecaea pedrosoi and Cladophialophora carrionii. Mycoses 56, 157-161. doi: 10.1111/j. 1439-0507.2012.02226.x

Lyon, J. P., Pedroso, E., Silva Azevedo Cde, M., Moreira, L. M., de Lima, C. J., and de Resende, M. A. (2011). Photodynamic antifungal therapy against chromoblastomycosis. Mycopathologia 172, 293-297. doi: 10.1007/s11046-0119434-6

Mannucci, E., Genovese, S., Monami, M., Navalesi, G., Dotta, F., Anichini, R., et al. (2014). Photodynamic topical antimicrobial therapy for infected foot ulcers in patients with diabetes: a randomized, double-blind, placebo-controlled study-the D.A.N.T.E (diabetic ulcer antimicrobial new topical treatment evaluation) study. Acta Diabetol. 51, 435-440. doi: 10.1007/s00592-0130533-3

Marsh, P. D. (2004). Dental plaque as a microbial biofilm. Caries Res. 38, 204-211. doi: $10.1159 / 000077756$

Martins, M., Uppuluri, P., Thomas, D. P., Cleary, I. A., Henriques, M., LopezRibot, J. L., et al. (2010). Presence of extracellular DNA in the Candida albicans biofilm matrix and its contribution to biofilms. Mycopathologia 169, 323-331. doi: 10.1007/s11046-009-9264-y

Motamedi, M., Ghasemi, Z., Shidfar, M. R., Hosseinpour, L., Khodadadi, H., Zomorodian, K., et al. (2016). Growing incidence of non-dermatophyte onychomycosis in Tehran, Iran. Jundishapur. J. Microbiol. 9:e40543. doi: 10. 5812/jjm.40543

Mowat, E., Butcher, J., Lang, S., Williams, C., and Ramage, G. (2007). Development of a simple model for studying the effects of antifungal agents on multicellular communities of Aspergillus fumigatus. J. Med. Microbiol. 56, 1205-1212. doi: 10.1099/jmm.0.47247-0

Nitzan, Y., Wexler, H. M., and Finegold, S. M. (1994). Inactivation of anaerobic bacteria by various photosensitized porphyrins or by hemin. Curr. Microbiol. 29, 125-131. doi: 10.1007/bf01570752

Nusbaum, A. G., Kirsner, R. S., and Charles, C. A. (2012). Biofilms in dermatology. Skin Ther. Lett. 17, 1-5. doi: 10.15226/2378-1726/5/1/00174

Orenstein, A., Kostenich, G., Roitman, L., Shechtman, Y., Kopolovic, Y., Ehrenberg, B., et al. (1996). A comparative study of tissue distribution and photodynamic therapy selectivity of chlorin e6, photofrin II and ALA-induced protoporphyrin IX in a colon carcinoma model. Br. J. Cancer 73, 937-944. doi: 10.1038/bjc.1996.185

Orlandi, V. T., Rybtke, M., Caruso, E., Banfi, S., Tolker-Nielsen, T., and Barbieri, P. (2014). Antimicrobial and anti-biofilm effect of a novel BODIPY photosensitizer against Pseudomonas aeruginosa PAO1. Biofouling 30, 883-891. doi: 10.1080/08927014.2014.940921

Pierce, C. G., Uppuluri, P., Tristan, A. R., Wormley, F. L. Jr., Mowat, E., Ramage, G., et al. (2008). A simple and reproducible 96-well plate-based method for the formation of fungal biofilms and its application to antifungal susceptibility testing. Nat. Protoc. 3, 1494-1500. doi: 10.1038/nport.2008.141
Piraccini, B. M., and Alessandrini, A. (2015). Onychomycosis: a review. J. Fungi 1, 30-43. doi: 10.3390/jof1010030

Pitangui, N. S., Sardi, J. C. O., Silva, J. F., Benaducci, T., Moraes da Silva, R. A., Rodríguez-Arellanes, G., et al. (2012). Adhesion of Histoplasma capsulatum to pneumocytes and biofilm formation on an abiotic surface. Biofouling 28, 711-718. doi: 10.1080/08927014.2012.703659

Plaetzer, K., Krammer, B., Berlanda, J., Berr, F., and Kiesslich, T. (2009). Photophysics and photochemistry of photodynamic therapy: fundamental aspects. Lasers Med. Sci. 24, 259-268. doi: 10.1007/s10103-0080539-1

Rajendran, R., Williams, C., Lappin, D. F., Millington, O., Martins, M., and Ramage, G. (2013). Extracellular DNA release acts as an antifungal resistance mechanism in mature Aspergillus fumigatus biofilms. Eukaryot. Cell 12, 420-429. doi: 10.1128/EC.00287-12

Ramage, G., Rajendran, R., Sherry, L., and Williams, C. (2012). Fungal biofilm resistance. Int. J. Microbiol. 2012:528521. doi: 10.1155/2012/ 528521

Seth, A. K., Geringer, M. R., Nguyen, K. T., Agnew, S. P., Dumanian, Z., Galiano, R. D., et al. (2013). Bacteriophage therapy for Staphylococcus aureus biofilminfected wounds: a new approach to chronic wound care. Plast. Reconstr. Surg. 131, 225-234. doi: 10.1097/PRS.0b013e31827e47cd

Sigurgeirsson, B. (2010). Prognostic factors for cure following treatment of onychomycosis. J. Eur. Acad. Dermatol. Venereol. 24, 679-684. doi: 10.1111/j. 1468-3083.2009.03487.x

Sigurgeirsson, B., Olafsson, J. H., Steinsson, J. B., Paul, C., Billstein, S., and Evans, E. G. (2002). Long-term effectiveness of treatment with terbinafine vs itraconazole in onychomycosis: a 5 -year blinded prospective follow-up study. Arch. Dermatol. 138, 353-357.

Soares, B. M., Alves, O. A., Ferreira, M. V., Amorim, J. C., Sousa, G. R., Silveira Lde, B., et al. (2011). Cryptococcus gattii: in vitro susceptibility to photodynamic inactivation. Photochem. Photobiol. 87, 357-364. doi: 10.1111/j.1751-1097.2010. 00868.x

Takahashi, H., Nakajima, S., Sakata, I., and Iizuka, H. (2014). Antifungal effect of TONS504-photodynamic therapy on Malassezia furfur. J. Dermatol. 41, 895-897. doi: 10.1111/1346-8138.12615

Taraszkiewicz, A., Szewczyk, G., Sarna, T., Bielawski, K. P., and Nakonieczna, J. (2015). Photodynamic inactivation of Candida albicans with imidazoacridinones: influence of irradiance, photosensitizer uptake and reactive oxygen species generation. PLoS One 10:e0129301. doi: 10.1371/ journal.pone.0129301

Toukabri, N., Corpologno, S., Bougnoux, M. E., El Euch, D., Sadfi-Zouaoui, N., and Simonetti, G. (2018). In vitro biofilms and antifungal susceptibility of dermatophyte and non-dermatophyte moulds involved in foot mycosis. Mycoses 61, 79-87. doi: 10.1111/myc.12706

Tuite, E. M., and Kelly, J. M. (1993). Photochemical interactions of methylene blue and analogues with DNA and other biological substrates. J. Photochem. Photobiol. B 21, 103-124.

Vila, T., Fonseca, B. B., Mml, D. A. C., Dos Santos, G. R. C., Ishida, K., BarretoBergter, E., et al. (2017). Candida albicans biofilms: comparative analysis of room-temperature and cryofixation for scanning electron microscopy. J. Microsc. 267, 409-419. doi: 10.1111/jmi.12580

Warshaw, E. M., Fett, D. D., Bloomfield, H. E., Grill, J. P., Nelson, D. B., Quintero, V., et al. (2005). Pulse versus continuous terbinafine for onychomycosis: a randomized, double-blind, controlled trial. J. Am. Acad. Dermatol. 53, 578-584. doi: 10.1016/j.jaad.2005.04.055

Conflict of Interest Statement: The authors declare that the research was conducted in the absence of any commercial or financial relationships that could be construed as a potential conflict of interest.

Copyright (c) 2019 Chen, Sun, Zhang, Chen, Zhong, Wu, Zheng and Zhao. This is an open-access article distributed under the terms of the Creative Commons Attribution License (CC BY). The use, distribution or reproduction in other forums is permitted, provided the original author(s) and the copyright owner(s) are credited and that the original publication in this journal is cited, in accordance with accepted academic practice. No use, distribution or reproduction is permitted which does not comply with these terms. 